\title{
CONGENITAL HEART DISEASE
}

\section{Endocardial and epicardial steroid lead pacing in the neonatal and paediatric age group}

\author{
F Udink ten Cate, J Breur, N Boramanand, J Crosson, A Friedman, J Brenner, \\ E Meijboom, N Sreeram
}

See end of article for authors' affiliations

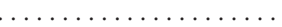

Correspondence to: Dr N Sreeram, Wilhelmina Children's Hospital, PO Box 85090, 3508 AB

Utrecht, Netherlands: nsreeram@azu.nl

Accepted 4 July 2002

\begin{abstract}
Aim: To compare the performance of steroid eluting epicardial and endocardial leads in infants and children requiring permanent pacing.

Methods: Evaluation of pacing and sensing characteristics, impedances, and longevity of 159 steroid eluting leads implanted in 95 children. Group A consisted of 24 children weighing less than $15 \mathrm{~kg}$ with 15 endocardial leads (five atrial, 10 ventricular) and 19 epicardial leads (five atrial, 14 ventricular). Group B consisted of 71 children weighing more than $15 \mathrm{~kg}$ with 106 endocardial leads $(56$ atrial, 58 ventricular) and 19 epicardial leads (nine atrial, 10 ventricular).

Results: Group A: Stimulation thresholds were lower for ventricular endocardial leads at implant (mean (SD) $0.84(0.54) \vee 1.59(0.64) \mathrm{V}, \mathrm{p}<0.014)$ and at two year follow up (ventricular 0.64 $(0.24) \vee 1.65(0.69) \mathrm{V}, \mathrm{p}<0.003)$. Impedance and sensing thresholds did not differ significantly at implant and follow up. Group B: Stimulation thresholds were lower for ventricular endocardial leads at implant $(0.72(0.48) \vee 1.48(0.58) \mathrm{V}, \mathrm{p}<0.001)$ and at follow up $(0.88(0.46) \vee 1.55(0.96) \mathrm{V}$, $p<0.009$ ). Impedance did not differ. Sensing thresholds were also better for ventricular endocardial leads at follow up (9.1 (5.2) v 14.2 (6.4) $\mathrm{mV}, \mathrm{p}<0.02)$. Complications requiring intervention occurred in both groups ( $n=7$ for endocardial $v \mathrm{n}=18$ for epicardial leads).

Conclusions: Endocardial and epicardial steroid eluting leads have comparable performance in the paediatric population.
\end{abstract}

$\mathrm{T}$ he introduction of steroid eluting pacing leads in the paediatric population has resulted in a notable improvement of lead performance and pacemaker longevity. ${ }^{1-5}$

Several studies have shown encouraging advantages using epicardial and endocardial steroid eluting leads instead of conventional non-steroid leads. ${ }^{6-14}$ The addition of steroid elution limits the inflammatory response at the electrode-tissue interface, resulting in better acute and chronic stimulation thresholds and improved battery longevity. ${ }^{15}$ There has been no systematic comparison of steroid eluting endocardial and epicardial leads in the paediatric age group. We report the results of a retrospective multicentre review comparing the performance and longevity of steroid eluting epicardial and endocardial leads in the paediatric population requiring permanent pacemaker treatment between August 1990 and February 2000.

\section{METHODS}

\section{Study patients}

The study group compromised all neonates and children who presented to one of three tertiary referral centres between August 1990 and February 2000 for implantation of a permanent pacing device with steroid eluting leads. In all, 95 patients underwent implantation of 121 endocardial and 38 epicardial steroid eluting leads (endocardial: 59 active fixation and 62 passive fixation; 101 bipolar and 20 unipolar; epicardial: seven bipolar and 31 unipolar). We reviewed patient and pacing data of all 95 children retrospectively and compared the performance and survival rate of endocardial and epicardial steroid eluting leads.

Patients were assigned to two groups: group A (neonates and small children) comprised 24 children weighing $\leqslant 15 \mathrm{~kg}$, and group B comprised 71 children weighing $>15 \mathrm{~kg}$. Patient characteristics and indications for pacing are shown in table 1. Group A showed no difference in patient demographics and characteristics. Age and weight at pacemaker implantation were significantly different between patients in group B who received endocardial or epicardial steroid eluting leads. The choice for epicardial or endocardial pacing systems in this study was based on institutional preference and the experience of the cardiologist.

The pacing measurements evaluated included stimulation voltage thresholds with a pulse width of $0.5 \mathrm{~ms}$, sensing thresholds ( $\mathrm{P}$ and $\mathrm{R}$ wave amplitudes), and impedances. At least one follow up measurement was available for all children. Patients were also reviewed for complications requiring reoperations or additional diagnostic testing during follow up. Lead failure was defined as unacceptably high thresholds making lead revision necessary.

Pulse generators and steroid eluting leads

Mode of pacing, implanted generators, and steroid eluting leads in group A and B are shown in tables 2 and 3, respectively. Group A consisted of 15 endocardial (five atrial, 10 ventricular) and 19 epicardial steroid leads (five atrial, 14 ventricular). Group B consisted of 106 endocardial steroid leads ( 49 atrial, 57 ventricular), eight endocardial non-steroid leads (seven atrial, one ventricular) and 19 epicardial steroid leads (nine atrial, 10 ventricular).

\section{Statistical analysis}

Study characteristics of group A and group B were compared using Student's $t$ test for continuous data and $\chi^{2}$ analysis or Fisher's exact test for binary variables. Data are presented as mean (SD). Follow up data on lead performance were analysed using the paired $t$ test. Probability values of $\mathrm{p}<0.05$ were considered significant for all tests.

\section{RESULTS}

Stimulation threshold

Group A

Atrial stimulation thresholds at implant and at the two year follow up were lower for endocardial steroid leads, but no 
Table 1 Characteristics of the 95 pacemaker patients

\begin{tabular}{|c|c|c|c|c|c|c|}
\hline & \multicolumn{3}{|c|}{ Group A: children weighing $\leqslant 15 \mathrm{~kg}$} & \multicolumn{3}{|c|}{ Group B: children weighing $>15 \mathrm{~kg}$} \\
\hline & Endocardial lead & Epicardial lead & $\mathrm{p}$ Value & Endocardial lead & Epicardial lead & $\mathrm{p}$ Value \\
\hline $\mathrm{n}$ & 10 & 14 & & 61 & 10 & \\
\hline $\operatorname{Sex}(M / F)$ & $5 / 5$ & $7 / 7$ & $>0.10$ & $31 / 30$ & $5 / 5$ & $>0.10$ \\
\hline Age at implantation (years) & $1.4(1.1)$ & $1.5(1.1)$ & $>0.10$ & $15.0(5.1)$ & $9.7(7.5)$ & $<0.05$ \\
\hline Weight at implantation $(\mathrm{kg})$ & $10.3(4.5)$ & $8.5(3.8)$ & $>0.10$ & $41.8(18.5)$ & $27.0(15.7)$ & $<0.02$ \\
\hline Follow up (years) & $2.0(1.0)$ & $2.4(2.2)$ & $>0.10$ & $2.1(1.9)$ & $2.8(1.3)$ & $>0.10$ \\
\hline \multicolumn{7}{|l|}{ Indication } \\
\hline Postoperative block & $4(40 \%)$ & $4(29 \%)$ & $>0.10$ & $25(41 \%)$ & $8(80 \%)$ & $>0.10$ \\
\hline CCAVB & $5(50 \%)$ & $7(50 \%)$ & $>0.10$ & $24(39 \%)$ & $1(10 \%)$ & $>0.10$ \\
\hline 2nd Degree block & 0 & $3(21 \%)$ & $<0.012$ & 0 & 0 & \\
\hline Sinus node dysfunction & 0 & 0 & & $9(15 \%)$ & $1(10 \%)$ & $>0.10$ \\
\hline Long QT syndrome & $1(10 \%)$ & 0 & $>0.10$ & $1(2 \%)$ & $1(10 \%)$ & $>0.10$ \\
\hline Cardiac arrest & 0 & 0 & & $2(3 \%)$ & 0 & $>0.10$ \\
\hline
\end{tabular}

statistical analysis could be undertaken owing to the small numbers. Ventricular stimulation thresholds were lower for endocardial leads than for epicardial leads both at implant $(\mathrm{p}<0.014)$ and at the two year follow up $(\mathrm{p}<0.003)$ (table 4 ). During follow up there was a decrease in stimulation threshold for endocardial steroid leads.

\section{Group B}

Stimulation thresholds were similar for atrial leads at implant and at the two year follow up in the two groups. Ventricular stimulation thresholds were lower for endocardial leads than for epicardial leads both at implant $(p<0.001)$ and at the two year follow up $(\mathrm{p}<0.009)$.

\section{Lead impedance}

\section{Group A}

Atrial lead impedance at implant and at the two year follow up was higher for endocardial leads than for epicardial leads. Ventricular lead impedance was similar at implant and at the two year follow up for both endocardial and epicardial leads (table 4). During follow up, impedance did not change for endocardial leads but decreased for epicardial leads.

\section{Group B}

Impedance for atrial leads and ventricular leads at implant and at the two year follow up did not differ significantly between endocardial and epicardial leads.

\section{Sensing thresholds}

\section{Group A}

$P$ wave amplitudes at implant were lower for endocardial leads than for epicardial leads. At the two year follow up P wave amplitudes were similar for both endocardial and epicardial leads (table 4). $\mathrm{R}$ wave amplitudes were not significantly different at implant and at the two year follow up.

\section{Group B}

P wave amplitudes at implant and at the two year follow up did not differ significantly. $\mathrm{R}$ wave amplitudes of endocardial leads were lower at implant, and remained lower at the two year follow up $(\mathrm{p}<0.02)$.

There were no significant intraindividual differences for pacing thresholds, sensing thresholds, or impedances at each follow up visit.

\section{Complications/further procedures \\ Group A}

No early complications requiring medical intervention occurred in children weighing less than $15 \mathrm{~kg}$ who received endocardial pacing systems. Six patients with epicardial pacemakers had procedure related or other complications: postpericardiotomy syndrome $(\mathrm{n}=2$, requiring hospital admission), pneumothorax $(\mathrm{n}=1)$, abdominal hernia at pacemaker location $(\mathrm{n}=1$; the hernia was surgically corrected), displacement of atrial lead $(\mathrm{n}=1)$, and ventricular lead failure $(\mathrm{n}=1)$.

Table 2 Pulse generators and pacing mode

\begin{tabular}{|c|c|c|c|c|}
\hline & \multicolumn{2}{|l|}{ Group A } & \multicolumn{2}{|l|}{ Group B } \\
\hline & Endocardial $(n=10)$ & Epicardial $(n=14)$ & Endocardial $(n=61)$ & Epicardial $(n=10)$ \\
\hline \multicolumn{5}{|l|}{ Generator (company) } \\
\hline Gem II (Medtronic) & - & - & 1 & - \\
\hline Kappa (Medtronic) & - & 1 & 24 & \\
\hline Legend (Medtronic) & - & 3 & 1 & 3 \\
\hline Thera (Medtronic) & 10 & 10 & 15 & 5 \\
\hline Affinity (Pacesetter) & - & - & 7 & - \\
\hline Synchrony (Pacesetter) & - & - & 6 & - \\
\hline Trilogy (Pacesetter) & - & - & 2 & - \\
\hline Paragon (Pacesetter) & - & - & 3 & - \\
\hline Delta (CPI) & - & - & 2 & - \\
\hline \multicolumn{5}{|l|}{ Pacing mode } \\
\hline DDD & $5(50 \%)$ & $5(36 \%)$ & $53(86 \%)$ & $9(90 \%)$ \\
\hline VVI & $5(50 \%)$ & $9(64 \%)$ & $3(5 \%)$ & $1(10 \%)$ \\
\hline AAl & - & - & $3(5 \%)$ & - \\
\hline VDD & - & - & $1(2 \%)$ & - \\
\hline Cardioverter & - & - & $1(2 \%)$ & - \\
\hline
\end{tabular}


Table 3 Characteristics of endocardial and epicardial steroid eluting leads

\begin{tabular}{|c|c|c|c|c|c|c|c|c|c|}
\hline & \multicolumn{4}{|c|}{ Endocardial } & & \multicolumn{4}{|c|}{ Epicardial } \\
\hline & \multicolumn{2}{|c|}{ Group A } & \multicolumn{2}{|c|}{ Group B } & & \multicolumn{2}{|c|}{ Group A } & \multicolumn{2}{|c|}{ Group B } \\
\hline & $\begin{array}{l}\text { Atrial } \\
(n=5)\end{array}$ & $\begin{array}{l}\text { Ventricular } \\
(n=10)\end{array}$ & $\begin{array}{l}\text { Atrial } \\
(n=49)\end{array}$ & $\begin{array}{l}\text { Ventricular } \\
(\mathrm{n}=57)\end{array}$ & & $\begin{array}{l}\text { Atrial } \\
(\mathrm{n}=5)\end{array}$ & $\begin{array}{l}\text { Ventricular } \\
(n=14)\end{array}$ & $\begin{array}{l}\text { Atrial } \\
(\mathrm{n}=9)\end{array}$ & $\begin{array}{l}\text { Ventricular } \\
(\mathrm{n}=10)\end{array}$ \\
\hline Medtronic & & & & & Medtronic & & & & \\
\hline 4023 & - & 1 & - & 2 & 2823 & 1 & 1 & 3 & 3 \\
\hline 4024 & - & - & 1 & - & 4965 & - & 8 & - & 1 \\
\hline 4033 & - & 2 & - & 11 & 4968 & 2 & 2 & - & 1 \\
\hline 4067 & 1 & 2 & 1 & 11 & 10366 & 2 & 2 & 6 & 5 \\
\hline 4068 & 3 & 4 & 19 & 9 & & & & & \\
\hline 4533 & 1 & - & 2 & - & & & & & \\
\hline 4568 & - & - & 5 & - & & & & & \\
\hline 5024 & - & - & - & 5 & & & & & \\
\hline 5038 & - & - & - & 1 & & & & & \\
\hline 5068 & - & - & 1 & 3 & & & & & \\
\hline 5076 & - & 1 & - & - & & & & & \\
\hline 5524 & - & - & 4 & 3 & & & & & \\
\hline 5534 & - & - & 2 & - & & & & & \\
\hline 5523 & - & - & 1 & - & & & & & \\
\hline 6945 & - & - & - & 1 & & & & & \\
\hline \multicolumn{10}{|l|}{ Tendril } \\
\hline DX 1388T & - & - & 8 & 5 & & & & & \\
\hline \multicolumn{10}{|l|}{ CPI } \\
\hline 4168 & - & - & 1 & 1 & & & & & \\
\hline 4268 & - & - & 1 & 1 & & & & & \\
\hline 4269 & - & - & 3 & 5 & & & & & \\
\hline
\end{tabular}

Late complications occurred in one endocardially paced patient who developed pacemaker syndrome 1.5 years after implantation of a VVIR pacemaker. Her pacemaker system was upgraded to a dual chamber device through the same subclavian vein. Pacemaker replacement was required in five patients who received epicardial leads because of battery depletion, 2.1 (1.0) years after implantation. Medical reinterventions occurred more often in patients receiving epicardial leads during the two year follow up.

\section{Group B}

Early complications in endocardially paced patients occurred in two patients who required repositioning of their atrial leads.
Postpericardiotomy syndrome complicated the early postoperative period in two epicardially paced patients, and wound infection in one patient.

Late interventions were required in four patients with endocardial leads and in five with epicardial leads. Two endocardially paced patients required repositioning of their atrial leads 2.1 and 2.4 years after implant. Pacemaker replacement because of battery depletion was necessary in two patients, at 3.0 and 4.0 years after implant. Three patients with epicardial leads required lead replacement (two atrial, one ventricular) owing to unacceptably high thresholds, at 1.0, 1.5 , and 1.8 years after implant, respectively. Pacemaker replacement was required in two patients, at 1.5 and 2.8 years after implantation.

Table 4 Pacing, sensing characteristics, and impedance at implantation and follow up

\begin{tabular}{|c|c|c|c|c|c|c|}
\hline & \multicolumn{3}{|c|}{ Group A: children weighing $\leqslant 15 \mathrm{~kg}$} & \multicolumn{3}{|c|}{ Group B: children weighing $>15 \mathrm{~kg}$} \\
\hline & Endocardial lead & Epicardial lead & $\mathrm{p}$ Value & Endocardial lead & Epicardial lead & $\mathrm{p}$ Value \\
\hline \multicolumn{7}{|l|}{ Atrial leads } \\
\hline Acute (n) & 5 & 3 & & 51 & 9 & \\
\hline Stimulation threshold (V) & $0.92(0.57)$ & 1.13 (0.09) & - & $0.73(0.33)$ & $0.90(0.40)$ & $>0.10$ \\
\hline Impedance (ohm) & $639(148)$ & 552 (129) & - & $563(163)$ & $615(142)$ & $>0.10$ \\
\hline Sensing threshold (mV) & $2.9(1.1)$ & $4.5(1.6)$ & - & $3.4(1.6)$ & $3.0(1.6)$ & $>0.10$ \\
\hline Chronic (n) & 4 & 2 & & 19 & 9 & \\
\hline Stimulation threshold (V) & $0.57(0.11)$ & $0.85(0.35)$ & - & $0.74(0.35)$ & $0.91(0.53)$ & $>0.10$ \\
\hline Impedance (ohm) & $626(136)$ & $609(152)$ & - & 612 (189) & $591(116)$ & $>0.10$ \\
\hline Sensing threshold $(\mathrm{mV})$ & $3.0(1.8)$ & $3.9(1.5)$ & - & $3.1(1.5)$ & $3.9(2.0)$ & $>0.10$ \\
\hline \multicolumn{7}{|l|}{ Ventricular leads } \\
\hline Acute (n) & 9 & 13 & & 55 & 11 & \\
\hline Stimulation threshold (V) & $0.84(0.54)$ & $1.59(0.64)$ & $<0.014$ & $0.72(0.48)$ & $1.48(0.58)$ & $<0.001$ \\
\hline Impedance (ohm) & 697 (162) & $610(180)$ & $>0.10$ & $656(183)$ & 683 (197) & $>0.10$ \\
\hline Sensing threshold (mV) & $9.7(4.9)$ & $12.8(7.2)$ & $>0.10$ & $9.1(6.2)$ & $12.6(7.4)$ & $>0.10$ \\
\hline Chronic (n) & 7 & 8 & & 24 & 10 & \\
\hline Stimulation threshold (V) & $0.64(0.24)$ & $1.65(0.69)$ & $<0.003$ & $0.88(0.46)$ & $1.55(0.96)$ & $<0.009$ \\
\hline Impedance (ohm) & $716(282)$ & $548(225)$ & $>0.10$ & $633(183)$ & 625 (178) & $>0.10$ \\
\hline Sensing threshold $(\mathrm{mV})$ & $9.6(1.9)$ & $9.6(3.3)$ & $>0.10$ & $9.1(5.2)$ & $14.2(6.4)$ & $<0.02$ \\
\hline
\end{tabular}

Data are mean $(\mathrm{SD})$ or $\mathrm{n}$.

-, no statistical analysis possible because of small number of measurements. 
There was no significant difference in lead survival between endocardial and epicardial leads in group B.

\section{Active fixation versus passive fixation}

In all, 59 endocardial active fixation leads (30 atrial, 29 ventricular) and 62 endocardial passive fixation leads (31 atrial, 31 ventricular) were implanted in 71 patients.

Atrial and ventricular stimulation thresholds were not significantly different at implant (atrial $0.73(0.32) \quad v \quad 0.74$ (0.38) V, p > 0.10; ventricular $0.71 \quad(0.28) v 0.57$ (0.36) V, $\mathrm{p}>0.10$ ), or at the two year follow up (atrial $0.55(0.15) v 1.10$ $(0.70) \mathrm{V}, \mathrm{p}>0.10$; ventricular 0.69 (0.34) $v 0.92$ (0.65) V, $\mathrm{p}>0.10)$. Atrial and ventricular lead impedance did not differ significantly between active and passive fixation leads at implant (atrial 553.7 (119.9) v 580.1 (168.9) ohm, p > 0.10; ventricular 629.3 (157.4) v 633.8 (171.6) ohm, p > 0.10), or at the two year follow up (atrial 628.9 (96.2) $v 675.6$ (203.8) ohm, p > 0.10; ventricular 576.2 (81.6) v 664.2 (246.6) ohm, $\mathrm{p}>0.10)$.

$\mathrm{P}$ wave and $\mathrm{R}$ wave amplitudes did not differ significantly at implant (atrial 3.13 (1.49) $v 3.49$ (1.34) mV, p > 0.10; ventricular $8.66(3.19) \vee 9.59(4.11) \mathrm{mV}, \mathrm{p}>0.10)$, or at two years after implantation (atrial 2.88 (1.19) $v 3.20$ (1.71) mV, $\mathrm{p}>0.10$; ventricular 9.21 (2.52) v 8.03 (2.83) mV, p > 0.10).

\section{DISCUSSION \\ Background}

Most children requiring permanent pacemaker treatment receive their pacemaker by the epicardial approach. ${ }^{45}$ The reasons for preferring the epicardial approach are patient size and anatomical considerations in children with abnormal venous connections or complex congenital heart defects. Implantation of endocardial leads in young patients also has to take account of somatic growth, ${ }^{10-14}$ which will require further advancement of the lead. The major concern with endocardial leads is the risk of venous thrombosis. ${ }^{7}$ There are no large studies addressing this issue in young patients with endocardial pacing systems, but lead size relative to the size of the vein appears to be an important factor in determining this risk.

On the other hand, the technique of epicardial permanent pacing is more invasive, often involving sternotomy. It is often complicated by post-pericardiotomy syndrome. ${ }^{9}$ Standard (non-steroid eluting) epicardial leads have been associated with a high incidence of rapidly increasing pacing and sensing thresholds following implantation, requiring early lead and generator replacement. In a recent publication, steroid eluting epicardial leads compared favourably with standard (nonsteroid eluting) endocardial leads. ${ }^{7}$ There has, however, been no study to date comparing endocardial and epicardial steroid eluting leads in children.

\section{The present study}

This study shows improved pacing thresholds for ventricular endocardial steroid eluting leads versus epicardial steroid eluting leads during short term follow up. At atrial level, no significant differences were observed. More epicardial leads and generators needed to be replaced for early lead or generator failure. In addition, there were fewer procedure related complications associated with implantation of an endocardial pacemaker system.

Most implanted endocardial systems in neonates and small children are single chamber ventricular pacemakers. Interestingly, during the study period the majority of epicardial pacemaker systems implanted at our institutions were also single chamber systems. This was true both for patients requiring pacemaker implantation for congenital atrioventricular (AV) block and those with acquired AV block following open heart surgical procedures for congenital heart defects. Two patients in our series who required pacing for congenital AV block developed dilated cardiomyopathy at follow up. This occurred exclusively in patients with dual chamber epicardial pacemaker systems.

This study demonstrates the efficacy of transvenous pacing, even in young infants. However, more needs to be learned about the potential for vascular complications in young patients receiving transvenous leads. None of the patients has required abandonment of a non-functional lead in the vascular system at short term follow up. This is evidently important, considering the lifelong requirement for pacemaker treatment and therefore the need for unobstructed vascular access. Newer techniques for recanalisation of occluded vessels using a laser sheath ${ }^{16}{ }^{17}$ are at present only applicable to larger children, and are not without complications.

\section{Study limitations}

There was a significant difference in the age distribution and weight at implant between patients receiving endocardial and epicardial leads in group B, the endocardially paced patients being older. This reflects institutional bias in the choice of method for permanent pacing, with the majority of centres choosing an epicardial pacemaker system in relatively younger patients. Various pulse generators were used in the three centres and epicardial leads were predominantly unipolar, whereas $83 \%$ of endocardial leads were bipolar. This may also contribute to the differences in lead survival and pacing characteristics.

\section{Conclusions}

This study shows comparable lead performances for endocardial and epicardial steroid eluting leads. Despite the apparently higher incidence of complications associated with epicardial pacing, epicardial permanent pacing in smaller children with preservation of the veins for later use appears to be a rational approach to pacing treatment in the paediatric population.

\section{Authors' affiliations}

F Udink ten Cate, J Breur, E Meijboom, N Sreeram, Wilhelmina Children's Hospital, Utrecht, Netherlands.

N Boramanand, A Friedman, Yale New Haven Hospital, New Haven, Connecticut, USA

J Crosson, J Brenner, The Johns Hopkins Hospital, Baltimore, Maryland, USA

\section{REFERENCES}

1 Santini $M$, De Seta $F$, the Italian multicenter study group on low output stimulation. Do steroid-eluting electrodes really have better performance than other state-of-the-art designs? PACE 1993;16:722-8.

2 Stojanov P, Djorjevic M, Velimirovic D, et al. Assessment of long-term stability of chronic ventricular pacing thresholds in steroid-eluting electrodes. PACE 1992;16:1417-20.

3 Kruse IB. Long-term performance of endocardial leads with steroid eluting electrodes. PACE 1986;9:1217-19.

4 Goldman-Cutler N, Karpawich PP, Cavitt D, et al. Steroid-eluting epicardial pacing electrodes: six year experience of pacing thresholds in a growing pediatric population. PACE 1997;20:2943-8.

5 Johns JA, Fish FA, Burger JD, et al. Steroid-eluting epicardial pacing leads in pediatric patients: encouraging early results. J Am Coll Cardiol 1992;20:395-401.

6 Wiegand UKH, Potratz J, Bonnemeier $\mathrm{H}$, et al. Long-term superiority of steroid elution in atrial active fixation platinum leads. PACE 2000;23: 1003-9.

7 Beaufort-Krol GCM, Mulder H, Nagelkerke D, et al. Comparison of longevity, pacing, and sensing characteristics of steroid-eluting epicardial versus conventional endocardial pacing leads in children. J Thorac Cardiovasc Surg 1999;117:523-8.

8 Radovsky AS, Van Vleet JF, Stokes KB, et al. Paired comparisons of steroid-eluting and nonsteroid endocardial pacemakers in dogs: electrical performance and morphologic alterations. PACE 1988;11:1085-94.

9 Gillette PC, Shannon C, Blair H, et al. Transvenous pacing in pediatric patients. Am Heart J 1983;105:843-7.

10 Ward DE, Jones S, Shinebourne EA. Long-term transvenous pacing in children weighing ten kilograms or less. Int J Cardiol 1987;15:112-15. 
11 Till JA, Jones S, Rowland E, et al. Endocardial pacing in infants and children $15 \mathrm{~kg}$ or less in weight: medium-term follow-up. PACE 1990;13:1385-92.

12 Molina J, Dunnigan AC, Crosson JE. Implantation of transvenous pacemakers in infants and small children. Ann Thorac Surg 1995.59:689-94.

13 Epstein ML, Knauf DG, Alexander JA. Long-term follow-up of transvenous cardiac pacing in children. Am J Cardiol 1986;57:889-90.

14 Gillette PC, Zeigler V, Bradham GB, et al. Pediatric transvenous pacing: a concern for venous thrombosis? PACE 1988;11:1935-39.
15 Mond HG, Stokes KB. The electrode-tissue interface: the revolutionary role of steroid elution. PACE 1992;15:95-107.

16 Bracke FA, Van Gelder LM, Sreeram N, et al. Exchange of pacing or defibrillator leads following laser sheath extraction of non-functional leads in patients with ipsilateral obstructed venous access. Heart 2000; 83:e12.

17 Madigan NP, Curtis JJ, Sanfelippo JF. Difficulty of extraction of chronically implanted tined ventricular endocardial leads. J Am Coll Cardiol 1984;3:724-31

\section{IMAGES IN CARDIOLOGY}

\section{Thrombosis in the proximal pulmonary artery stump in a Fontan patient}

$\mathrm{T}$

he patient is an 8 year old boy born with double outlet right venricle, mitral atresia, hypoplastic left ventricle, and pulmonary stenosis who underwent an atrial septectomy as a neonate. He suffered a stroke at the age of 2 years, which manifested as left hemiparesis. Computed tomographic scan of the head revealed infarction in the region of the basal ganglia. He was placed on aspirin and an intensive regimen of physical therapy, which resulted in progressive improvement in his neurological deficit, though compliance with medication was questionable. A year later he had a Fontan operation during which the main pulmonary artery was ligated distal to the pulmonary valve. Five years after surgery a routine surveillance echocardiogram revealed an echogenic mass in his pulmonary artery stump. This was confirmed on angiography shown below (anteroposterior (left panel) and lateral (right panel) angiograms showing the ovoid lucency of the clot in the pulmonary artery stump which lies to the left and posterior to the aorta). Despite the absence of symptoms, his past history and the known risk of embolic strokes in the Fontan population prompted urgent surgical removal of the thrombus. The pulmonary valve leaflets were oversewn and the cul-de-sac of the pulmonary artery stump was obliterated.

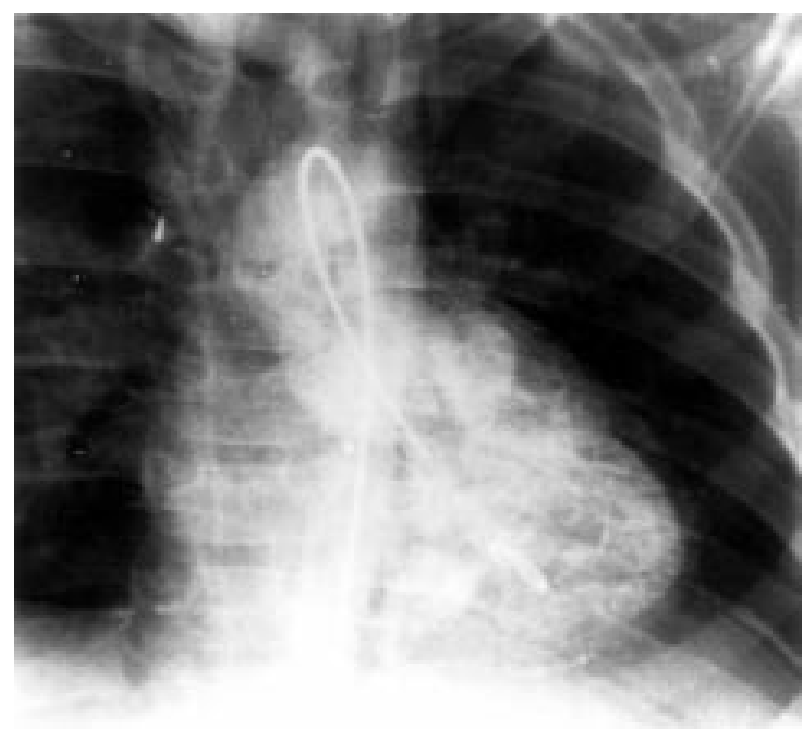

It is now recognised that this procedure, rather than pulmonary artery ligation, should be performed at the time of the Fontan operation. These images illustrate an uncommon but potentially serious and easily preventable complication in Fontan patients. They also reinforce the fact that even in asymptomatic patients with a single ventricle and a patent pulmonary valve, the pulmonary artery stump must be carefully imaged at frequent intervals to exclude thrombus formation.

N Madan

B W Robinson

M L Jacobs

Brobinson7001@aol.com

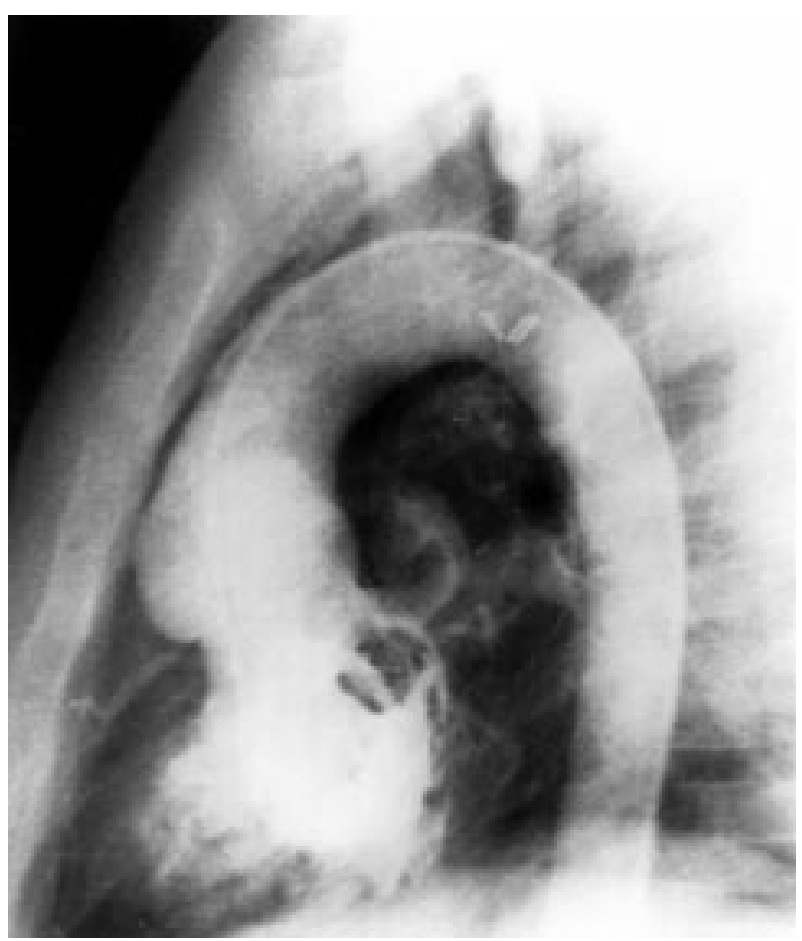

